Journal of Marine Systems

October 2016, Volume 162, Pages 1-3

http://dx.doi.org/10.1016/i.jmarsys.2016.06.004

http://archimer.ifremer.fr/doc/00342/45325/

(c) 2016 Published by Elsevier B.V.

\title{
Progress in marine science supported by European joint coastal observation systems: The JERICO-RI research infrastructure
}

Puillat Ingrid ${ }^{1,{ }^{*}}$, Farcy Patrick ${ }^{2}$, Durand D. ${ }^{3}$, Karlson B. ${ }^{4}$, Petihakis G. ${ }^{5}$, Seppälä J. ${ }^{6}$, Sparnocchia S. ${ }^{7}$

${ }^{1}$ Ifremer, Centre de Brest, LOPS UMR 6523, CS10070, 29200 Plouzané, France

${ }^{2}$ Ifremer, Centre de Brest, DS, CS10070, 29200 Plouzané, France

${ }^{3}$ NIVA, Gaustadalleen 21, 0349 Oslo, Norway

${ }^{4}$ SMHI, Oceanography Sven Kallfelts gata, 15, 426 71, Vastra Frolunda, Sweden

${ }^{5}$ HCMR, Thalassocosmos, Gournes Pediados, P.O. Box 2214, Heraklion, Crete, GR 71 003, Greece

${ }^{6}$ SYKE Marine Research Centre, P.O. Box 140, 00251 Helsinki, Finland

${ }^{7}$ CNR-ISMAR, Viale Romolo Gessi 2, 34123 Trieste, Italy

* Corresponding author : Ingrid Puillat, email address : ingrid.puillat@ifremer.fr 


\section{Coastal observations and monitoring: The scientific, technological and societal context}

. Coastal systems are of the most productive ones although they are the most impacted by direct pressures from human activities. These ecosystems exhibit a high level of complexity with many different and interconnected processes operating at various spatial and temporal scales and providing a range of ecosystem services. Coastal observations are tremendous importance in order to understand those complex marine processes. Moreover, they support the use and further development of coastal ocean numerical models, including physical models and coupled physical-biogeochemical models. Coastal data have also many applications in the domain of coastal engineering such as for instance in the design of a coastal structure, or in the prevention of extreme events (e.g. flooding). As a consequence, the number of marine observing systems has quickly increased around European coastal seas, under the pressure of both monitoring requirements and marine research. Present demands for such observing systems include reliable, high-quality and comprehensive observations of key environmental parameters, automated platforms and sensors systems for continuous observations, as well as autonomy over long time periods. In-situ data collected can be combined with remote sensing and/or models to detect, understand and/or forecast the most crucial coastal processes over extensive areas within the various marine environments.

In Europe, significant heterogeneity exists when it relates to marine observing systems, would it be technological design, measured parameters, practices for maintenance and quality control, as well as quality standards for sensors and data exchange. This can partly be explained by the fact that, most "coastal observatories" have been designed following national/regional research priorities and mainly undertaken through a series of short-term research projects. A main challenge for the European marine research community is therefore to harmonise the technologies, increase the consistency and the sustainability of these infrastructures by sharing know-how, establishing best practices and $s$ agreeing on a consensual roadmap for the future of coastal observatories within a shared pan-European framework.

These considerations led about thirty institutions in Europe to organise their coastal observation systems in a pan European Research Infrastructure: the JERICO-RI (www.jerico-ri.eu), and to build up this integrated infrastructure following a long-term approach This article and the following in this special issue of Journal of Marine Systems are focusing on some results of the FP7 JERICO project (2011-2015), which is briefly presented in the next section. The section 3 introduces the articles of this special issue, presenting the most relevant results supported by the use and the further development of the JERICO-RI. Some general conclusions are drawn in section 4.

In the following lines and pages "JERICO" will refer to the FP7 project, whereas "JERICONEXT" is referring to the ongoing H2O2O follow-up project. "JERICO-RI" is referring to the integrated research infrastructure, which development is supported by these projects.

\section{The JERICO FP7 project in a nutshell}

JERICO was a 4-year long infrastructure project co-funded by the European Commission in the 7th Framework Programme under the grant agreement $n^{\circ} 262584$. JERICO is being developed by a consortium of 27 partners from 17 European countries under the coordination of IFREMER (Institut Français de Recherche pour l'Exploitation de la MER), the French national research centre in charge of sustainable management of the sea.

The main objective of the JERICO stage, which worked to establish a Pan European approach for a European coastal marine observatory network, was to integrate 
infrastructures and technologies such as fixed buoys, piles, moorings, ferryboxes and gliders. JERICO is also built upon existing infrastructures and regional networks at European scale including the European Global Ocean Observation System (EuroGOOS). JERICO contributed to address the challenge of observing the complexity and high variability of coastal areas at Pan-European level, in the framework established by European Directives (Water Framework Directive: WFD; European Commission, 2000 Marine Strategy Framework Directive: MSFD, European Commission, 2008) and the marine core service of the European Earth observation programme (Copernicus) by:

- setting up a European Research Infrastructure for coastal observations based on existing systems in European coastal and shelf seas,

- supporting standardization of methodologies for the benefit of data quality, data availability and cost efficiency,

- promoting the cost-effective use of the facilities,

- stimulating the development of new automated systems for the operational monitoring of the coastal marine environment, with focus on the biochemical compartment.

JERICO projects under the Framework Programme FP7 \& H2020 are clearly driving a process aiming at bringing together the representative European coastal observatory operators, enhancing their coordination and promoting the cost-effective use of their facilities, in order to support the efficient provision of essential research and monitoring networks.

In order to reach this target, the consortium of the JERICO-RI promotes: (i) networking activities for standardisation issues from the sensors level up to the data management, (ii) Joint Research Activities (JRA), (iii) TransNational Access (TNA) to JERICO-RI facilities and platforms and data access.

i) Networking activities led to the definitions of best practices for the design, implementation, maintenance and distribution of coastal observing systems, as well as the definition of quality standards.

ii) Joint research activities were conducted in order to identify new and strategic technologies to be implemented in the next generation of European coastal observatories. Focus was given on emerging technologies and on the observation of the biochemical compartment.

Access to JERICO-RI was provided through Trans-National Access to research scientists outside the project consortium. The selection was made following open calls and based on scientific excellence. The objective was to promote the potential of JERICO-RI facilities and platforms when used in synergy.

Articles in this special issue present some results obtained in the framework of TNA and JRA within the JERICO project.

\section{Some relevant outcomes from JERICO and next steps}

Twelve articles compose this special issue, presenting results of collaborative research activities in the fields (i) new technology and methodologies for the observation/measurement of macrofauna, algae, carbonate system and contaminants, and their integration into existing observing platforms. (ii) joint deployment and exploitation of gliders, ferrybox systems or fixed platforms, together with other information sources like imagery or modelling; (iii) data assimilated into models to improve simulation/forecasting $\mathrm{s}$ and to perform optimisation of the infrastructure network. The articles are presented and referenced in the following sub-section. 


\subsection{New technology development and methodologies}

With regards to the monitoring of the biological compartment, developments focused on methods for the analysis of images and videos. To monitor and study the macrofauna the main objective was to develop a flexible and scalable imaging platform that could be used in the widest possible set of ecological situations. Details are presented in the article by Romero-Ramirez et al. (2016). This led to the conception of new software: AVIExplore, for marine benthic application. For the pelagic domain, work was dedicated to the study of changes in zooplankton community composition and size structure by Zooscan and sampling. An imaging-based protocol has been applied to a high frequency time series of zooplankton obtained in a coastal site of the NW Mediterranean Sea, Villefranche Bay, France. Results are given in Romagnan et al. (2016).

The developments undertaken to study the carbonate system and marine contaminants were supported by TNA experiments. Results are published in 3 articles referred hereafter.

To quantify the rate of ocean acidification and air-sea $\mathrm{CO}_{2}$ fluxes, new automated high precision technologies are needed to measure different components of the marine carbonate chemistry. Reggiani et al. (2016) report metrological approaches behind the spectrophotometric $\mathrm{pH}$ detection procedure and present field-based observations from a deployment of the $\mathrm{pH}$ detection system in the Norwegian Coastal Current in 2015. GonzálezDávila et al. (2016) present the assessment of the $\mathrm{pH}$ variability from a one year-study using a new photometric pH sensor moored on a buoy in the Saronikos Gulf.

Chemical pollution is known to be high in specific coastal regions, influencing the health of the ecosystems, sustainability of ecosystem services and the use of aquatic organisms as food and feed. Mapping and monitoring the distribution of contaminants in marine environment is needed and Brumovský et al. (2016) provide premium example how to combine such monitoring with more traditional oceanographic research using ships of opportunity. This article provides new directions for cost-efficient monitoring of marine contaminants and provides information on some chemical compounds never before identified in offshore waters.

\subsection{Examples of some specific research actions supported by the JERICO-RI}

The JERICO-RI and TNA actions driven in the FP7 project supported, among others, 2 studies of the mesoscale-induced variability on general circulation and biogeochemistry: one in the Bay of Biscay, presented in Caballero et al. (2016) and one in the Algerian Basin (North Western Mediterranean Sea) in Cotroneo et al. (2016). Both benefited from the glider fleet enrolled in the JERICO-RI, as well as from information from satellite images. In the Baltic Sea, investigations of nearshore hydrodynamic, lithodynamic, and morphodynamic processes were supported by fixed platforms, as presented in Ostrowski et al. (2016). In the same region, another study compared data acquired by Ferrybox system mounted on a cargo vessel cruising in the Gulf of Bothnia, the Baltic proper and the Kattegat, twice a week. Water samples from the Ferrybox-system were analysed from the period 2011-2013 to investigate the quality of the Ferrybox underway data (Karlson et al., 2016).

\subsection{Data assimilation and modelling with the JERICO data}

The JERICO data were used in data assimilation systems dedicated to run Observing System Experiments (OSEs) and Observing System Simulation Experiments (OSSEs). Using jointly the two types of numerical experiments are helpful to evaluate the impact of existing observing networks on data assimilation schemes, and to design new and more efficient ones, by combing real data and artificial ones. Charria al. (2016) demonstrate, for instance, that the impact of combining simulated glider tracks with existing 
temperature/salinity observations in the spring season is dependent on the vertical stratification conditions where surface Ferrybox is the most efficient observing system. In fact, glider tracks improve the simulation in the Loire River plume (northern part of the Bay of Biscay, stratified condition) but do not in the Western English Channel (homogeneous condition). Aydoğdu et al. (2016), applied OSEs to evaluate real temperature observations collected by an established Fishery Observing System (FOS) network in the Adriatic Sea, demonstrating that the collected data improve the analysis significantly, especially during the stratification season. OSSEs instead were run to study the impact of the implementation of a CTD (conductivity-temperature-depth) sensor in place of the existing temperature sensor installed on the fishing gears, demonstrating that the assimilation of salinity does not improve the analysis significantly during the winter and spring seasons.

One characteristic of long term deployed infrastructures is their ability to acquire long time series at high temporal frequency. With benefit of technology developments and real-time data, scientists have to handle an increasing data flow, which is not appropriately addressed by the existing marine data systems. In order to step over this challenge, a specific data set was used for testing several methods of time series analysis (Kbaier et al., 2016).

\section{General conclusions}

The JERICO-RI contributes to the international effort on integrating a Global Earth Observation System of Systems (GEOSS), and to the marine core service of the European Earth observation programme Copernicus, by providing coastal data for operational ocean observations and forecasting. The coastal ocean, especially the water column, continues to be severely under-sampled in some locations and according to specific scientific objectives or policy requirements. Under this consideration, the JERICO-RI also supports answering to some of the environmental and societal challenges in the framework of the European Water Directive and of the Marine Strategy Framework Directive.

Through the JERICO FP7 project, the JERICO-RI, has been designing as an infrastructure organisation devoted to the automated in-situ coastal and shelf-sea observations, completing observations from satellites (handled by Copernicus) and from the automated in-situ open ocean systems, such as ERIC EURO-ARGO and ESFRI EMSO. In the framework of the JERICO-NEXT project, the JERICO-RI is further developing, through integrating observations and monitoring of the biological and biochemical compartment, with focus on the benthic and pelagic biodiversity, the carbon cycle, and emerging marine pollutants. As such it is not restricted to the automated sampling and operational observation. Moreover, two important platform types have been included, providing the premise of a European HF radar network and coastal cable observatories.

As a consequence, JERICO-RI is an important contribution to the global ocean observing infrastructure that Europe contributes in building, and to a future European Ocean Observing System (European Marine Board, 2013, "Navigating the Future IV").

\section{Acknowledgements:}

The Coordination team the JERICO FP7 project is very grateful to the consortium, for its fruitful collaborative work but also for the trustful relationship felt during these four years. This was the key nutrient to build upon toward the successful JERICO-NEXT proposal. As such this acknowledgement is dedicated to any staff member of the partner institutions, including administrative and technical staff as well as researchers. TNA experiments have been evaluated by a dedicated panel during the lifetime of the project and followed up by CNRIsmar (Italy). The coordination team greatly appreciated their work and helpful comments.

The guest editors and the authors thank the $\sim 40$ reviewers for their constructive comments 
and suggestions.

Finally, we acknowledge the European commission for the funding of the JERICO project under the FP7 contract agreement \#262584, with special considerations for the project Officer Agnès Robin for her great support.

\section{References:}

Aydoğdu, A., Pinardi, N., Pistoia,J., Martinelli, M., Belardinelli, A., Sparnocchia, S., 2016. Assimilation experiments for the Fishery Observing System in the Adriatic Sea, Journal of Marine Systems, this issue. http://dx.doi.org/10.1016/j.jmarsys.2016.03.002.

Brumovský, B., Bečanová, J. , Kohoutek, J., Thomas, H., Petersen, W., Sørensen, K., Sáňka, O., Nizzetto, L., 2016. Exploring the occurrence and distribution of contaminants of emerging concern through unmanned sampling from ships of opportunity in the North Sea, Journal of Marine Systems, this issue. http://dx.doi.org/10.1016/j.jmarsys.2016.03.004.

Caballero, A., Rubio, A., Ruiz, S., Le Cann, B., Testor, P., Mader, J., Hernández, C., 2016. South-Eastern Bay of Biscay eddy-induced anomalies and their effect on chlorophyll distribution, Journal of Marine Systems, this issue.

http://dx.doi.org/10.1016/j.jmarsys.2016.04.001.

Charria, G., Lamouroux, J., De Mey, P., 2016. Optimizing observational networks combining gliders, moored buoys and FerryBox in the Bay of Biscay and English Channel, Journal of Marine Systems, this issue. http://dx.doi.org/10.1016/j.jmarsys.2016.04.003.

Cotroneo, Y., Aulicino, G., Ruiz, S., Pascual, A., Budillon, G., Fusco, G., Tintoré, J., 2016. Glider and satellite high resolution monitoring of a mesoscale eddy in the algerian basin: Effects on the mixed layer depth and biochemistry, Journal of Marine Systems, this issue. http://dx.doi.org/10.1016/j.jmarsys.2015.12.004.

European Commission, 2000. Establishing a framework for Community action in the field of water policy (Water Framework Directive). Directive 2000/60/EC of the European Parliament and of the Council, Official Journal of the European Communities, L 327/1, 1-72.

European Commission, 2008. Establishing a framework for community action in the field of marine environmental policy (Marine Strategy Framework Directive). Directive 2008/56/EC of the European Parliament and of the Council, Official Journal of the European Communities, $L$ 164/19, 1-22.

European Marine Board, 2013. Navigating the Future IV. Position Paper 20 of the European Marine Board, Ostend, Belgium. ISBN: 9789082093100.

González-Dávila, M., Santana-Casiano, J. M., Petihakis, G., Ntoumas, M., de Tangil, M. S., Krasakopoulou, E., 2016. Seasonal pH variability in the Saronikos Gulf: A year-study using a new photometric $\mathrm{pH}$ sensor, Journal of Marine Systems, this issue.

http://dx.doi.org/doi:10.1016/j.jmarsys.2016.03.007

Karlson, B., Andersson, L.S, Kaitala, S., Kronsell, J., Mohlin, M., Seppälä, J., WillstrandWranne, A., 2016., A comparison of FerryBox data vs. monitoring data from research vessels for near surface waters of the Baltic Sea and the Kattegat, Journal of Marine Systems, this issue. http://dx.doi.org/10.1016/j.jmarsys.2016.05.002.

Kbaier Ben Ismail, D., Lazure, P., Puillat, I., 2016. Statistical properties and time-frequency analysis of temperature, salinity and turbidity measured by the MAREL Carnot station in the coastal waters of Boulogne-sur-Mer (France), Journal of Marine Systems, this issue. http://dx.doi.org/10.1016/j.jmarsys.2016.03.010.

Ostrowski, R., Schönhofer, J., Szmytkiewicz, P., 2016. South Baltic representative coastal field surveys, including monitoring at the Coastal Research Station in Lubiatowo, Poland, Journal of Marine Systems, this issue. http://dx.doi:10.1016/j.jmarsys.2015.10.006. 
Reggiani, E. R., King, A.L., Norli, M., Jaccard, P., Sørensen, K., Bellerby, R. G.J. FerryBoxassisted monitoring of mixed layer $\mathrm{pH}$ in the Norwegian Coastal Current, Journal of Marine Systems, this issue. http://dx.doi.org/10.1016/j.jmarsys.2016.03.017.

Romagnan, J.B., Aldamman, L., Gasparini, S., Nival, P., Aubert, A., Jamet, J.L., Stemmann, L., 2016. High frequency mesozooplankton monitoring: Can imaging systems and automated sample analysis help us describe and interpret changes in zooplankton community composition and size structure - An example from a coastal site, Journal of Marine Systems, this issue. http://dx.doi.org/10.1016/j.jmarsys.2016.03.013.

Romero-Ramirez, A., Grémare, A., Bernard, G., Pascal, L., Maire O., Duchêne, J.C. Development and validation of a video analysis software for marine benthic applications, 2016. Journal of Marine Systems, this issue. http://dx.doi.org/10.1016/j.jmarsys.2016.03.003. 